\title{
Victor Yavorsky
}

\section{NEW PRINCIPLES IN THE POLYMERIC SULFUR TECHNOLOGY}

\author{
Lviv Polytechnic National University, 12 Bandera str., 79013 Lviv, Ukraine \\ Yavorsky@polynet.Iviv.ua
}

Received: February 11, 2008

\begin{abstract}
The new method of polymeric sulfur obtaining based on the polymerization of atoms instead of molecules has been proposed. It has been proven that using the new method essentially increases polymerization degree (over $90 \%$ ).
\end{abstract}

Keywords: sulfur, homochain, cyclic octasulfur, atomic sulfur, polymerization.

\section{Introduction}

The history of the human society and industry development shows that the role and place of some chemical elements in nature and men's life, as well as their production and using often do not correspond to their contents in the Earth's crust.

Sulfur is a striking example of all above mentioned. Although its content in the Earth's crust is only $5 \cdot 10^{-2} \mathrm{wt} \%$, it does not belong to the dispersed elements due to its mainly concentrated state. Moreover, sulfur stands second after oxygen as anion-forming element and binds a considerable part of metals in sulfides and sulfates form. However, the most important fact is that sulfur has the range of features, which are not characteristic of the majority of chemical elements and of $p$-elements of its sub-group in particular. Owing to its specific and remarkable features sulfur played a considerable role in the development of humanity and its relations with nature.

\section{Results and Discussion}

The ability to form stable homochains is an essential distinction of sulfur. Such an ability is due to higher energy of two bonds in the S-S-S homochain $(263000 \cdot 2=$ $=526000 \mathrm{~J} / \mathrm{mol}$ ) as compared with the $\mathrm{S}=\mathrm{S}$ molecule $(210000 \cdot 2=420000 \mathrm{~J} / \mathrm{mol})$. For oxygen, to the contrary, the bonds in the $\mathrm{O}=\mathrm{O}$ molecule are stronger $(494000 \mathrm{~J} / \mathrm{mol})$ in comparison with two bonds in O-O-O homochain $(420000 \mathrm{~J} / \mathrm{mol})$. Only in carbon the binding energy between atoms in chain structure is higher from that in sulfur (330000 against $263000 \mathrm{~J} / \mathrm{mol}$ for sulfur). Due to the above mentioned sulfur atoms are highly capable of interacting between each other with the formation of cyclic or chain molecules, followed by the formation of great amount of different allotrope modifications with geometrical isomerism. Therefore sulfur physical and chemical properties substantially depend upon its allotrope composition and production conditions [1].

It should be mentioned that sulfur homochains have a zigzag form. This is due to the unpaired electrons of mutually perpendicular p-orbitals of atom taking part in their formation.<smiles>CSSSSSC</smiles>

Crown shaped $\mathrm{S}_{8}$ cyclic molecules (cyclic octasulfur) are most stable (Fig. 1).

Cyclic octasulfur forms three crystalline allotropic forms. Under normal conditions rhombic form ( $\alpha$-sulfur) with melting temperature of $385.8 \mathrm{~K}$ is the most stable. However, it remains stable only up to $368.5 \mathrm{~K}$.

Within the temperature range of $368.5-385.8 \mathrm{~K}$ $\alpha$-sulphur is transformed into monocline modification ( $\beta$-sulfur) with further melting. When cooled the melt transforms into -sulfur, which then gradually converts into more stable rhombic form.

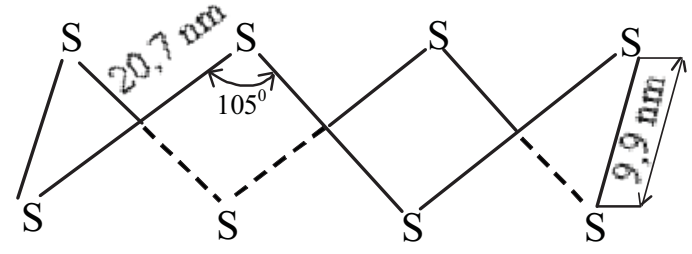

Fig. 1. Structure of $\mathrm{S}_{8}$ molecule

Sulfur melt contains practically all allotropic forms, correlation between which is determined mainly by the temperature. Thus within the temperature range of 392.9- 
$428 \mathrm{~K}$ liquid sulfur contains octocyclic molecules, which begin to collapse at the temperatures of $428-433 \mathrm{~K}$, converting into the open chains. Further heating results in the chains length reduction $\left(\mathrm{S}_{6}, \mathrm{~S}_{4}, \mathrm{~S}_{2}\right)$. At $433 \mathrm{~K}$ an intensive process of the sulfur chains polymerization takes place. The process is more intensified with the temperature increase, but the length of the polymeric chains reduces.

Sulfur has a clearly defined ability to sublimation. A noticeable vapor pressure above solid sulfur is formed already at $280 \mathrm{~K}$. Such pressure above liquid sulfur sharply increases and at $717.6 \mathrm{~K}$ sulfur begins to boil. The vapor contains $\mathrm{S}_{8}, \mathrm{~S}_{6}, \mathrm{~S}_{4}$ and $\mathrm{S}_{2}$ molecules. $\mathrm{S}_{2}$ part increases with the increase of the temperature and at $1873 \mathrm{~K}$ the sulfur vapor contains only atoms. It is known [1] that the less atoms the molecule of sulfur contains the more reactive it is. It means that monoatomic sulfur, which is a biradical with perpendicular unpaired p-electrons, is the most active. It is these valence electrons that build polymeric molecules.

The technology of such specific type of sulfur as polymeric sulfur is based on the tendency of chain molecules of liquid sulfur to interact. Due to its extraordinarily valuable specific properties application of polymeric sulfur instead of ordinary (rhombic) sulfur considerably improves the quality of wares and substantially encourages technical progress in the sulfur-consuming branches of industry. The main consumers of the polymeric sulfur are rubber-technical industry, which produces the bulk of rubber wares for different machines, mechanisms, devices etc. and building industry, which applies sulfur concretes, sulfur ceramics, sulfur bitumens, etc.

The traditional methods of polymeric sulfur production consist in melt-quench of sulfur or its vapors in the presence of stabilizers. In both cases such sulfur molecules as $\mathrm{S}_{8}, \mathrm{~S}_{6}$ and $\mathrm{S}_{4}$ are polymerized; the polymerization degree being not higher than $40-50 \%$. According to the technical specifications (TS) the content of the polymeric modification in the finished product must exceed $90 \mathrm{wt} \%$. Therefore, the rhombic sulfur needs to be separated from the polymeric one. For this purpose the grinded product is treated with the organic solvents (products of oil processing, tetrachlorethylene, benzene etc.) at high temperatures dissolving (extracting) the rhombic sulfur. Then the solution is cooled to crystallize the rhombic sulfur. Sulfur crystals with around $2 \%$ of the solvent are separated. The solvent is heated and reextracted.

The complexities of this process are the following:

- the rhombic sulfur solvents are toxic, explosive and flammable;

- the presence of solvent residues in the rhombic sulfur crystals limits the product application and make its storage complicated;
- the rhombic sulfur can be cleaned from the organic substances by heated air or overheated water steam [1]. In both cases either contaminated air or steam must be cleaned. Thus the separation of the polymeric sulfur from the obtained product is accompanied by the range of accessory processes which are quite complicated in technological and ecological aspects and thereby deteriorating technical and economic indexes. Due to the above reasons there is no industrial production of polymeric sulfur on the territory of CIS and the world demand for polymeric sulfur is considerably undersupplied .

Naturally the question arises what the major cause of such low efficiency of the existent technological principles of polymeric sulfur production is.

In an attempt to find an answer to the above question a deep comprehensive analysis of sulfur physical and chemical properties as well as technological bases of the existent polymeric sulfur technologies have been conducted. The results of such analysis along with our stored scientific achievements in sulfur related problems allow us to conclude that the main cause of polymeric sulfur productions imperfection is that these productions are based on the principles of polymerization of sulfur molecules with different number of atoms in them. These molecules are formed by sulfur thermal processing. At definite temperatures they are polymerized, but during quenching the system itself tends to form the most stable structure - cyclic octasulfur. Stabilizers which "saturate" free valence sulfur p-electrons retard this process but obviously do not eliminate it fully. The polymerization degree can be slightly increased by selecting active stabilizers and by optimizing the heating and quenching conditions but these measures do not remove the principal cause of the low polymerization degree.

The cardinal solution of the problem is using polymerization of atoms instead of molecules (atomic polymerization). There are all reasons to suppose that under certain conditions the atomic polymerization would proceed with high speed and completeness allowing to obtain polymeric sulfur rather than mixture of different sulfur modifications as the final product. So far no arguments against this conclusion have emerged.

With the aim to confirm our theoretical conclusions we conducted investigations which proved the efficiency of sulfur atoms polymerization. The polymerization degree of above $90 \%$ was reached [2]. The obtained positive results confirmed the topicality of our scientific investigations and brought up the question about obtaining the atomic sulfur.

Atomic sulfur may actually be obtained by different methods. Prima facie the thermal method is the simplest. 
The lump sulfur is melted, heated to boiling and then its vapor is overheated to the temperatures of $1873 \mathrm{~K}$, at which sulfur exists only in the atomic state. Lump sulfur is a commodity and relatively cheap product (up to 40 dollars per 1 ton). Melting heat of rhombic sulfur is $49800 \mathrm{~J} / \mathrm{mol}$, evaporation heat is $286900 \mathrm{~J} / \mathrm{mol}$, heat capacities of solid, liquid and vaporous sulfur are also low. Hence, this process involves low power inputs. However, there are serious problems with the process equipment. Heat application should be conducted through a wall. In order to provide sufficient thermal transfer the temperature of the heat carrier (apparently flue gases) has to be above $2000 \mathrm{~K}$. It is known that the coefficient of thermal transfer through a wall is insignificant in the gas-gas system. Consequently this process will need a large heating surface operating at high temperatures. At the same time it should be stressed that the sulfur vapors, especially atomic sulfur vapors, penetrate into the crystal lattice of metals destroying it. Thus high temperatures, low coefficient of thermal transfer, complexity of constructive materials selection, "sulfuric" corrosion are the main factors which render practical realization of this method of atomic sulfur obtaining impossible.

Obtaining atomic sulfur from hydrogen sulfide by its atomization, which takes place at $1963 \mathrm{~K}$ and higher temperatures, is one of the promising techniques. The heat of hydrogen sulfide formation is minor $(20150 \mathrm{~J} / \mathrm{mol}$ against $241840 \mathrm{~J} / \mathrm{mol}$ for water). The hydrogen sulfide resources are enormous. The basic source of $\mathrm{H}_{2} \mathrm{~S}$ is natural gas, where the hydrogen sulfide content increases with the increase of the depth of the natural gas occurrence [1]. The hydrogen sulfide is obtained as a by-product in petroleum refining, by-product-coking and other industries. To date the hydrogen sulfide has become the main raw material for the sulfur obtaining (gas sulfur) and gas industry has transformed into gas-chemical industry.

It should be stressed again that hydrogen sulfide is a complex raw material containing two valuable elements Sulfur and Hydrogen. Taking into account a relatively low hydrogen sulfide formation heat and importance of the hydrogen energetics development, a conclusion about the topicality of the problem of obtaining atomic sulfur and hydrogen from hydrogen sulfide can be drawn.

Analyzing the atomic sulfur and hydrogen obtaining process from the point of view of specific power inputs, temperature range, equipment design, corrosive processes, etc., it can be inferred that hydrogen sulfide thermal dissociation has all drawbacks inherent in the process of obtaining atomic sulfur from lump sulfur via the thermal method. In addition to this the above process implies intensive hydrogen corrosion. As a consequence practical implementation of the thermal dissociation of hydrogen sulfide is problematic. That is why there is an urgent need in discovering effective and economically sound methods of hydrogen sulfur atomization.

Acid decomposition of sulfur oxygen-containing compounds, in which sulfur has intermediate oxidation degree, is an encouraging method of atomic sulfur obtaining. Thiosulfates, in which sulfur has the oxidation degree of +2 , are of the greatest interest. As it is known, such oxidation degree is unstable, hence in an acid medium disproportionation reaction proceeds with obtaining of atomic sulfur and its oxide (IV). The results of our experiments aimed at the development of effective processes of obtaining atomic sulfur from hydrogen sulfide and thiosulfates will be represented in our next publications.

\section{Conclusions}

The atomic polymerization is a brand new tendency in polymeric sulfur obtaining. In future atomic sulfur may be obtained via the acid decomposition of sodium thiosulfate and the hydrogen sulfide plasmolysis.

\section{References}

1. Menkovskiy M. and Yavorsky V.: Tekhnologiya sery. Khimiya, Moskwa 1985.

2. Yavorsky V. et al.: A.s. 1271006 SSSR.

\section{НОВІ ПРИНЦИПИ В ТЕХНОЛОГІЇ ПОЛІМЕРНОЇ СІРКИ}

Анотація. Запропоновано принципово новий спосіб одержання полімерної сірки, який трунтується на полімеризації атомів, а не молекул, i дає змогу суттєво підвищити ступінь полімеризачії (понад $90 \%$ ).

Ключові слова: сірка, гомоланцюг, циклооктасірка, атомарна сірка, полімеризація. 
